\title{
Avaliação da Aprendizagem na Era da Informação
}

\author{
ADRIANO RODRIGUES RUIZ \\ Professor da Universidade Estadual de Maringá e Professor do Programa de \\ Mestrado em Educação da Universidade do Oeste Paulista - Unoeste \\ arruiz@uol.com.br
}

\begin{abstract}
Resumo
Neste artigo, tendo como pano de fundo as possibilidades abertas pelas tecnologias de comunicação e informação, situamos a avaliação de aprendizagem como importante recurso para a formação de hábitos intelectuais despertos para relações criativas na busca de conhecimentos. Apontamos a necessidade de que a avaliação, nos contratos didáticos em construção, seja re-significada a partir de olhares atentos à paciência para aprender, ao zelo em distanciar-se da massificação, ao desapego às respostas, ao olhar carinhoso às perguntas e à multiplicidade de opções na escolha de caminhos para aprendizagens. A atitude curiosa e paciente diante do não-conhecido se transformaria na mais rica indicação dos progressos vividos por um aprendiz.

Palavras-chave: avaliação de aprendizagem, tecnologias de comunicação e informação, paciência para aprender.
\end{abstract}

\begin{abstract}
Resumen
En este artículo, al considerar como telón de fondo las posibilidades abiertas por las tecnologías de comunicación e información, ubicamos la evaluación de aprendizaje como importante recurso para la formación de hábitos intelectuales despertados para las relaciones creativas en la búsqueda de conocimientos. Señalamos la necesidad de que la evaluación, en los contratos didácticos en construcción, sea re-significada a partir de miradas atentas a la paciencia para aprender, al cuidado en distanciarse de la masificación, al despego a las respuestas, al mirar cariñoso a las preguntas y a la multiplicidad de opciones en la elección de caminos para aprendizajes. La actitud curiosa y paciente frente al no-conocido se convertiría en la más rica indicación de los avances corridos por un aprendiz. Palabras-clave: evaluación de aprendizaje, tecnologías de comunicación e información, paciencia para aprender.
\end{abstract}

\begin{abstract}
In this article, with the possibilities opened by information and communication technology as a background, we propose learning assessment as an important resource to form intellectual habits towards creative relations in the quest for knowledge. Evaluation in developing didactic contracts must be re-signified by focusing on patience to learn, on caring about getting away from massification, on an unconcern for answers, on a caring look at questions and at multiple options in choosing ways of learning. A curious and patient attitude towards the unknown would be the most fruitful indication of a learner's progress. Key words: learning evaluation, communication and information technology, patience to learn.
\end{abstract}




\section{SITUANDO O PROBLEMA}

Existe uma rica teia de sabedorias que explica a vida escolar, orientando os diferentes fazeres, apontando os bons e os maus caminhos. Ampara-se em concepções acerca de aprendizagem, conhecimento, bom aluno, bom professor, percursos para aquisição de conhecimentos, instrumental tecnológico, compromissos etc. Como uma espécie de síntese, situa-se a avaliação da aprendizagem.

A avaliação da aprendizagem, no fundo, é expressão dos fins que atribuímos à educação, das nossas crenças epistemológicas e da forma como cuidamos do nosso poder de controle sobre os alunos. Oferece guarida às diversas manifestações da cultura escolar, entre elas o culto ao armazenamento de conhecimentos. É sobre isso que fala a clássica metáfora bancária de Paulo Freire: a educação como ato de depositar, em que os educandos são os depositários e o educador o depositante e conferente.

A avaliação tem papel importante na formação de hábitos intelectuais, auxilia os alunos no mapeamento do que é mais importante no dia-a-dia escolar e no universo dos estudos e das aprendizagens. Com ela, o professor explicita por onde passeiam seus sonhos educacionais: pelos vales serenos das respostas ou pelas bifurcações vizinhas de turbulências e de incertezas, habitadas pelas perguntas.

Com a chegada da internet e de todo o aparato tecnológico destinado à comunicação, o professor que fazia da transmissão de informações o ponto central de seu ofício perdeu-se em um imenso vazio. A avaliação, nos contratos didáticos em construção, carece de resignificação a partir de olhares amplos que incidam em paisagens ainda pouco conhecidas. Na amplidão de paisagens que anunciam possibilidades e compromissos, identificamos a necessidade de cultivar-se a paciência para aprender, o zelo em distanciar-se da massificação, o desapego às respostas, o olhar carinhoso às perguntas e à multiplicidade de opções na escolha de caminhos para aprendizagens.

O professor que se dirigia tranqüilamente à sala de aula, com a lição bem preparada, com absoluto domínio da situação, é uma figura do passado, pois o território bem demarcado daquele que ministra aulas passou a coexistir com muitos outros. Como conseqüência, a avaliação da aprendizagem precisa se munir de novos olhos e de novas atenções, para captar as construções dos alunos em seus diferentes percursos, pois o processo de conhecer tornou-se mais importante e significativo que o conhecimento adquirido. 


\section{A PACIÊNCIA PARA APRENDER}

A idéia de inovação, muitas vezes, é traiçoeira por privilegiar as aparências em detrimento de ações mais profundas e radicais. Em educação, faz-se necessário algo difícil e incerto: mudanças que alcancem nossas predisposições mentais para conceber aprendizagem, autogoverno, vocações do humano, felicidade... Pertencem ao território da paciência para a busca, da escuta de perguntas abafadas pela pressa, da identificação de obstáculos a serem superados e da rejeição de respostas para perguntas que não compreendemos.

Parece-nos evidente que uma característica do mundo educacional é sua propensão para saltar obstáculos, ao invés de superá-los. Superação exige a tomada de consciência de lacunas, de pré-concepções que impedem novas formas de olhar, do fascínio que diferentes vitrines exercem ao direcionar decisões, do apego a dogmas que falam da transmissão de conhecimentos...

O caudaloso rio de informações que é oferecido nos dias atuais, ao invés de alargar horizontes, pode soterrar questões importantes, dando-nos a sensação de que conhecemos as respostas e os meios para alcançá-las. Porém, de que valem as respostas quando não compreendemos profundamente o sentido das perguntas? Quando nos constrangemos diante da lentidão de comportamentos mais interrogativos? Quando o fazer se sobrepõe ao compreender?

A radicalidade na formulação e compreensão do significado das perguntas seria um dos pilares da arte de inovar no mundo educacional. A tecnologia traz, em sua essência, essa mensagem?

Não! A tecnologia tem seus laços mais fortes com o fazer, de preferência rápido, com economia de tempo. A inserção do computador, em diferentes espaços de nossas vidas, faz da rapidez um atributo que distingue o moderno do antiquado; demarca passado, presente e anuncia o futuro.

Preocupado com o abandono da paciência na busca, Postman (2002), ao falar da devoção do humano ao deus tecnologia, interroga: irá a velocidade de resposta se tornar, mais do que nunca, uma qualidade definidora da inteligência? Que papel será reservado à nossa principal ferramenta intelectual: a pergunta?

Ao entregar-se ao enlevo da velocidade, o humano separa a ação da reflexão, perdendo o talento para se deter no ainda não-conhecido, em possíveis analogias com situações já vividas, na tomada de distância para perceber melhor as coisas, para pôr à prova evidências, para tirar as 
verdades de seus pedestais... Automatiza procedimentos, caminha pelos sulcos profundos das rotinas.

Fromm (s/d, p. 100) lembra-nos de que, nos últimos séculos, o homem ocidental vive obcecado pelo trabalho e pela necessidade de atividade constante. A preguiça e a atividade compulsiva são identificadas por Fromm como complementares, pois a mutilação da atividade produtiva dá lugar à inatividade ou à atividade excessiva. A atividade produtiva caracteriza-se pela alternância rítmica entre atividade e repouso. Trabalho, amor e pensamento produtivos só são possíveis se a pessoa pode ficar, quando necessário, quieta e a sós consigo mesma.

A vinculação da tecnologia com a pressa, com a angústia gerada pela sensação de falta de tempo, tem sido apontada sob diversas formas e por meio de diferentes linguagens. Por exemplo, Michael Ende (1995, p. 53), em seu delicioso Momo e o senhor do tempo, lembra-nos da existência de um mistério muito grande, que, no entanto, faz parte do dia-a-dia. Todos os seres humanos participam dele, embora poucos reflitam sobre ele. A maioria simplesmente o aceita, sem mais indagações. Esse mistério é o tempo.

Ende fala que tempo é vida e que a vida mora no coração. Diante da manifesta vontade das pessoas economizarem tempo, o autor pergunta: o que significa tempo poupado? Ora, o tempo é vida, a vida mora nos corações. Quanto mais as pessoas poupam tempo, mais pobre, superficial e fria se torna sua existência e mais alheias elas se tornam a si mesmas.

Sten Naldony (1990), em A descoberta da lentidão, ao contar a história do pesquisador inglês John Franklin, mostra-nos como é salutar que cada pessoa meça o tempo com os próprios padrões. Contudo, destaca o autor, à medida que os relógios e os homens foram ficando mais exatos - ao invés de tranqüilidade e comedimento - observa-se apenas escassez de tempo e pressa. Naldony, retratando o ambiente vivido na Inglaterra da primeira metade do século XIX, escreve que pegar a corrente do relógio se tornara mais freqüente que pegar o chapéu, e que raramente se ouvia alguém praguejar. A expressão: Não tenho tempo! substituíra as pragas.

Em uma rota paradoxal, a pressa cresce à medida que a humanidade vai contando com recursos mais sofisticados para "facilitar" sua vida. A máquina tem sido tomada como padrão de eficiência, como uma espécie de referência para se pensar a produtividade do humano.

Em um mundo tão apressado, a avaliação da aprendizagem precisa considerar que a capacidade de se deter pacientemente em diferentes leituras é mais importante do que dispor de fascinantes ferramentas que nos auxiliam em diferentes fazeres. $\mathrm{O}$ desafio não consiste em recensear, armazenar e repetir informações, mas em cultivar a paciência para 
enriquecer nosso processo de pensar, conhecer, estabelecer vínculos, viver em sintonia com o belo e com a poesia das perguntas.

\section{A RESISTÊNCIA À MASSIFICAÇÃO}

O conformismo intelectual ganha força ao procurarmos amparo naquilo que é moda ou consensual, fugindo de possíveis desconfortos advindos da singularidade própria das posturas mais autônomas e arredias à massificação. Einstein (1981, p. 12) alerta que é a pessoa humana, livre, criadora e sensível que modela o belo e exalta o sublime, ao passo que as massas continuam arrastadas por uma dança infernal de imbecilidade $e$ de embrutecimento.

Atento aos compromissos da educação, Adorno (2000, p. 144) argumenta que: a educação por meio da família, na medida em que é consciente, por meio da escola, da universidade teria, neste momento de conformismo onipresente, muito mais a tarefa de fortalecer a resistência do que fortalecer a adaptação.

Com a mesma inquietação, Rollo May (2001, p. 40) insiste que os talentos e a iniciativa de cada indivíduo precisam ser redescobertos e utilizados como base para um trabalho que contribua para o bem da comunidade, em lugar de desfazer-se no cadinho coletivista da conformidade.

A percepção da falta de zelo com a preservação das singularidades pessoais, levou Erich Fromm (1987, p. 24) a escrever que:

o sonho de sermos senhores independentes de nossas vidas terminou quando despertamos para o fato de que todos nos tornamos peças infimas da máquina burocrática, com nossos pensamentos, sentimentos e gostos manipulados pelo governo, pela indústria e pelas comunicações de massa que controlam tudo.

Com preocupações do mesmo gênero, Krishnamurti (2001, p. 80-81) denuncia: o Estado soberano não quer que seus cidadãos sejam livres, que pensem por si mesmos, e os controla por meio da propaganda, por meio de falsas interpretações da história, etc. Assim, a educação está se tornando cada vez mais um meio de ensinar o que pensar e não como pensar. O próprio Krishnamurti acrescenta que a educação convencional dificulta o pensar independente e que a padronização do homem o conduz à mediocridade.

Com o otimismo característico de quem acredita em sua vocação para a emancipação, Rogers (2001) identifica o humano como processo de auto-realização, avançando na direção de experiências mais desafiadoras. Como processo de transformação procura, pelo desenvolvimento de suas potencialidades, alcançar a dignidade. Para ele, a pessoa é única e vive em um mundo sempre 
novo, em reiterada mudança e aberta para a construção de novas significações.

Apontando caminhos, Jacquard (1988, p. 155) fala que em nosso tempo amplia-se a tomada de consciência de que as diferenças nos enriquecem e que a lição que a biologia oferece é a de que nossa riqueza coletiva é feita de nossa diversidade. O "outro" é precioso para nossa vida na medida em que é diferente de nós. A nossa necessidade superficial, de conforto intelectual, impele-nos a reduzir tudo a tipos e a julgar segundo a conformidade aos tipos; mas a riqueza está na diferença.

Orientado por esse mesmo olhar, Tedesco (2001, p. 70) observa que as tecnologias nos dão informações e permitem a comunicação, condições necessárias do conhecimento e da comunidade. Ele alerta, contudo, que a construção do conhecimento e da comunidade é tarefa das pessoas, não dos aparatos. A contribuição da tecnologia é permitir que o tempo, que agora é utilizado para transmitir ou comunicar, seja dedicado à construção de conhecimentos e vinculos, sociais e pessoais, mais profundos.

Pensar a construção de conhecimentos e de vínculos implica considerar possibilidades para a formação de coletivos inteligentes. Pierre Lévy (1996, p. 112) diz que para esse processo é necessário aprofundar a abertura da consciência individual ao funcionamento da inteligência social $e$ melhorar a integração e a valorização das singularidades criadoras que os indivíduos e os pequenos grupos humanos formam nos processos cognitivos e afetivos da inteligência coletiva. Ele acrescenta que antes de ser uma lei da história, trata-se de um projeto transmitido, enriquecido, reinterpretado a cada geração e infelizmente suscetível de esclerose ou de esquecimento.

Lévy (1996, p. 119) ainda nos lembra de que as pessoas são todas inteligentes à sua maneira e que os grupos decepcionam com freqüência. Sabe-se que, numa multidão, as inteligências das pessoas, longe de se adicionar, tendem a se dividir. A burocracia e as formas de organização autoritárias asseguram uma certa coordenação, mas às custas da supressão das iniciativas e do aplainamento das singularidades. O que permite a valorização recíproca das inteligências nos pequenos grupos são as boas regras de organização $e$ de escuta mútua.

Nessa perspectiva, a avaliação deitaria olhos carinhosos à produção divergente, aos estilos pessoais de busca de conhecimentos, à criatividade na formulação de perguntas, à multiplicidade de encantamentos diante de belezas dos mais diferentes matizes etc. $\mathrm{O}$ distanciamento dos alunos da tendência de aderir às unanimidades da massa seria um indicador de êxito da empreitada educativa. 


\title{
A UTOPIA DE UM NOVO CLIMA INTELECTUAL
}

\author{
Nossa utopia é a construção de uma \\ sociedade inteligente ou uma sociedade \\ inteligentemente conduzida?
}

Pierre Lévy

Ganha consistência a percepção de que o modo como pensamos e percebemos o funcionamento da educação podem estar contaminados por equívocos. É possível que tenhamos chegado a um período em que o antigo bom-senso que orientava procedimentos centrados no armazenamento de conhecimentos tenha perdido sua luz. Por isso, ouvemse vozes a cobrar ousadia na busca de caminhos.

Seymour Papert (1997) afirma que muitas das crenças e práticas que compõem o cenário humano e seu arsenal de estratégias não serão reescritas a não ser que as pessoas construam melhores formas de pensar do que as que nos conduziram ao estágio atual. As dificuldades que escurecem os nossos horizontes serão superadas somente se percebidas fora dos focos rotineiros.

Bachelard (1999, p. 17) lembra-nos de que tratamos o conhecimento como o avarento trata o dinheiro, padecemos do mal do "ouro acariciado". Somos reféns de nossas posses, das verdades nas quais nos apegamos, das lições que aprendemos a repetir. Esquecemo-nos de que, no fundo, o ato de conhecer dá-se contra um conhecimento anterior, destruindo conhecimentos mal estabelecidos, superando o que no próprio espírito é obstáculo à espiritualização.

Com seu linguajar poético, ao falar que muitos professores universitários não passariam no vestibular, Rubem Alves (2003) completa dizendo que não seria por terem memória fraca, mas por terem memória inteligente. Burras não são as memórias que esquecem, mas as memórias que nada esquecem... A memória inteligente esquece o que não faz sentido. A memória viaja leve. Não leva bagagem desnecessária.

Jerome Bruner (2006, p. 172), ao escrever sobre desafios da educação, lembra-nos que talvez o mais importante seja o levantamento de novas hipóteses que não considerem correto aquilo que se tornou habitual e que tenhamos a coragem de reconhecer o que não entendemos e nos permitir um olhar novo e inocente. A inocência dessa busca pode se inspirar nestes versos de Mário Quintana (1996, p. 36): 


\section{Utopias}

Se as coisas são inatingíveis... oras! Não é motivo para não querê-las... Que tristes os caminhos, se não fora A presença distante das estrelas!

Algo mais distante podem ser, por exemplo, relações didáticas que permitam a tomada de consciência da transitoriedade dos conhecimentos. $\mathrm{O}$ antigo contrato didático partia da premissa da aprendizagem (quase) instantânea; ele reservava ao professor a incumbência da transmissão e ao aluno o do bom e dedicado ouvinte. $\mathrm{O}$ behaviorismo forneceu aporte teórico para consolidação e longevidade dessas teias de relações nos ambientes escolares. Progressivamente, fomos sendo convidados a perceber nosso papel de arquitetos e co-construtores de um mundo contingente. Não meramente desorientados perante a riqueza de suas conexões, mas inspirados por sua transitoriedade e pela dinâmica de suas incertezas.

A beleza do contingente, diz Savater (2004, p. 109), é que celebra tanto o temor do que nos é dado quanto a sombra do que nos falta. Sabemos que, por mais cuidadosos que sejamos, nossas convicções mais bem documentadas podem se revelar equivocadas, antes ou depois. Os erros desanimam os apressados e os nostálgicos que anseiam a preservação dos dogmas, mas ensinam pouco a pouco aos demais.

Nestes versos de Fernando Pessoa, podemos viajar pelos mesmos horizontes:

$$
\begin{aligned}
& \text { A verdade, se ela existe, } \\
& \text { Ver-se-á que só consiste } \\
& \text { Na procura da verdade, } \\
& \text { Porque a vida é só metade. }
\end{aligned}
$$

Respostas que parecem tão claras podem, a qualquer momento, se revelar insuficientes ou equivocadas. Isso dá vida à compreensão de limites da confiabilidade de nossos conhecimentos e dá vida à fé no élan que nos leva à busca, à compreensão de que conhecer é um jogo infindo.

O que são as verdades?

Com Popper (1972), aprendemos que, no mundo da ciência, nossas verdades são aquelas afirmações concordantes com os fatos reais que resistem às tentativas de se provar sua falsidade. Não dispomos de mapas que nos conduzem à verdade, porém possuímos critérios que podem nos ajudar a reconhecer o erro e a falsidade. Nessa perspectiva, a busca da 
verdade é um exercício de modéstia no diálogo com incertezas, mas não de renúncia.

Jacquard (1989, p. 63) lembra-nos de que o fim das certezas reflete a tomada de consciência da inesgotável riqueza do real, ante nossa busca de informações sobre ele. Aceitar a incerteza não é renunciar ao conhecimento, mas perceber que o pano de fundo em que representamos a realidade mudou. Após o Deus dos relógios e do demônio das fornalhas, surge um ser cuja complexidade torna-o capaz de autonomia, capaz de utilizar o passar do tempo para criar coisas novas, para inventar sentido, um ser que não é Deus nem demônio: o Homem.

A percepção de que vivemos em um mundo contingente e de que dispomos de instrumentos intelectuais para o diálogo com as incertezas pode ser um alento para interrogarmos aquilo que nos parece normal e necessário. Vale lembrar que, como salienta Jung (1986), a educação é aquilo que alguém faz para si e por si, é o processo de auto-aprendizagem. Por essa via, educar é uma empreitada de cunho espiritual; envolve a criação de climas intelectuais suficientemente humildes e pacientes para o convívio com respostas provisórias e com a tomada de consciência das limitações dos cinco sentidos como ferramentas para conhecer e, também, de quão enganosas podem ser as opiniões.

Isso impõe um importante desafio ao professor: alargar o horizonte dos alunos! Ou seja, deixar a avaliação penetrar no campo da subjetividade, transformando-a em instrumento de aberturas para o autoconhecimento, o olhar visionário e otimista em relação ao futuro, a busca de comportamentos mais autodirigidos, a semeadura da ética do amorpróprio e da responsabilidade pessoal.

Pertence ao mundo do "educar-se" o arrojo do estudante em planejar e administrar sua própria aprendizagem, em explorar espaços privilegiados para o conhecer, tais como a biblioteca, a internet, a televisão, o cinema, os eventos científicos ou culturais...

É a leveza para a mudança, a compreensão do sentido efêmero da validade dos conhecimentos e a sabedoria de como aprender que, segundo Rogers (1985), constitui a única coisa que faz qualquer sentido como objetivo para a educação no mundo moderno.

O "educar-se" é um processo que tem muitos momentos e que exige muitos parceiros. É a relação da pessoa consigo mesma, que exige o tempo do pensar, dos rodeios... é a relação com o outro; por exemplo, com o professor, o exercício da escuta, da compreensão das razões do outro... Por isso o "educar-se para aprender" é um exercício de paciência do estudante com ele próprio, do estudante para com o professor e do professor para com o estudante, e do professor com ele mesmo. 


\section{CONSIDERAÇÕES FINAIS}

Vivemos o momento em que ganha corpo um novo mapeamento da ação do professor, o seu espaço expandiu-se. A biblioteca, a internet, o cinema, os laboratórios... são extensões da sala de aula. $\mathrm{O}$ território bem demarcado daquele que ministra aulas passou a coexistir cooperativamente com muitos outros.

Terreno novo, instrumentos modernos, caminhos múltiplos... abrem ao professor horizontes mais largos, inseguros e perigosos. O detentor de informações perdeu o encanto. Como conseqüência, a avaliação da aprendizagem precisa se munir de novos olhos, e de novas atenções, para captar as construções dos alunos em seus diferentes percursos.

A tradição de avaliar os alunos enquanto caminham pela areia, nos trilhos bem demarcados, empenhados em reter informações que o professor transmitiu, tornou-se um marco a ser superado. A inovação estaria em olharmos com carinho para os momentos em que eles entram nas águas claras onde os trilhos inexistem, em que o fazer exige reflexão e criação.

Em outras palavras, o processo vivido na busca, seleção e construção de sínteses é a expressão viva de climas intelectuais abertos a aprendizagens. Bohm (1980) salienta que a capacidade de perceber ou pensar de modo diferente é mais importante que o conhecimento ganho. Os conhecimentos adquiridos registram êxitos pontuais, o mais significativo é o processo de conhecer.

A paciência para se deter no ainda não-conhecido, em possíveis analogias com situações já vividas, na tomada de distância para se perceber melhor as coisas... são células do tecido de possíveis inovações. A paciência, a postura curiosa diante da situação ainda não-conhecida, parece-nos ser um bom caminho para aproximar a ação da reflexão; o não sei! seria objeto de ação-reflexão, o germe do talento para criar soluções. A escola seria um ateliê de experimentação, de diálogo com os muitos (ainda) não sei! A atitude diante do não-conhecido se transformaria na mais rica indicação dos progressos vividos por um aprendiz.

\section{REFERÊNCIAS BIBLIOGRÁFICAS}

ADORNO, T. W. Educação e emancipação. São Paulo: Paz e Terra, 2000.

ALVES, R. Memórias burras nunca esquecem. Folha de S. Paulo, Caderno Sinapse, 25 mar. 2003. 
BACHELARD, G. A Formação do espírito científico. Rio de Janeiro: Contraponto, 1999.

BOHM, D. A Totalidade e a ordem implicada. São Paulo: Cultrix, 1980.

BRUNER, J. Sobre a teoria da instrução. São Paulo: Ph Editora, 2006.

EINSTEIN, A. Como vejo o mundo. Rio de Janeiro: Nova Fronteira, 1981.

ENDE, M. Momo e o senhor do tempo. São Paulo: Martins Fontes, 1995.

FREIRE, P. Pedagogia do oprimido. Rio de Janeiro: Paz e Terra, 1981.

FROMM, E. Ter ou ser? Rio de Janeiro: Guanabara Koogan, 1987. Análise do homem. São Paulo: Círculo do Livro, s/d.

JACQUARD, A. Elogio à diferença. São Paulo: Martins Fontes, 1988. - A Herança da liberdade. São Paulo: Martins Fontes,1989.

KRISHNAMURTI, J. A Educação e o significado da vida. São Paulo: Cultrix, 2001.

JUNG, C. G. O Desenvolvimento da personalidade. Petrópolis: Vozes, 1986.

MAY, R. O Homem à procura de si próprio. Petrópolis, RJ: Vozes, 2001.

NALDONY, S. A Descoberta da lentidão. Rio de Janeiro: Rocco, 1990.

LÉVY, P. O Que é o virtual? São Paulo: Editora 34, 1996.

PAPERT, S. A Família em rede. Lisboa: Relógio D'água, 1997.

PESSOA, F. Ficções do interlúdio. São Paulo: Companhia das Letras, 1998.

POPPER, K. A Lógica da pesquisa científica. São Paulo: Cultrix; Edusp, 1972.

POSTMAN, N. O Fim da educação. Rio de Janeiro: Graphia, 2002. 
QUINTANA, M. Antologia poética. Porto Alegre: L\&PM, 1996.

ROGERS, C. Liberdade de aprender em nossa década. Porto Alegre: Artes Médicas, 1985.

. Tornar-se pessoa. São Paulo: Martins Fontes, 2001.

SAVATER, F. A Importância da escolha. São Paulo: Planeta, 2004.

TEDESCO, J. C. O Novo pacto educativo. São Paulo: Ática, 2001.

Recebido em: outubro 2006

Aprovado para publicação em: janeiro 2007 